\title{
FoxM1 is associated with metastasis in colorectal cancer through induction of the epithelial-mesenchymal transition
}

\author{
BAO-YING FEI ${ }^{1}, \mathrm{XUJUN}^{2} \mathrm{HE}^{2}, \mathrm{JIE} \mathrm{MA}^{3}, \mathrm{MEI} \mathrm{ZHANG}^{3}$ and RUI CHAI ${ }^{4}$ \\ ${ }^{1}$ Department of Gastroenterology, Tongde Hospital of Zhejiang Province, Hangzhou, Zhejiang 310012; \\ ${ }^{2}$ Key Laboratory of Gastroenterology of Zhejiang; Departments of ${ }^{3}$ Pathology and ${ }^{4}$ Anorectal \\ Surgery, Zhejiang Province People's Hospital, Hangzhou, Zhejiang 310014, P.R. China
}

Received July 26, 2015; Accepted February 3, 2017

DOI: $10.3892 / \mathrm{ol} .2017 .7022$

\begin{abstract}
The aim of the present study was to investigate the role of forkhead box M1 (FoxM1) in epithelial-mesenchymal transition (EMT) and metastasis in colorectal cancer (CRC). Immunohistochemical assays were performed to detect FoxM1 and epithelial (E-) cadherin protein expression in 92 CRC, 61 colonic adenoma and 32 wild-type colonic tissue samples. Quantitative polymerase chain reaction (qPCR) assays were performed to determine the expression levels of FoxM1 and E-cadherin mRNAs in $30 \mathrm{CRC}$ and adjacent normal mucosal tissues. RNA interference was used to knock down endogenous FoxM1 expression in CRC cell lines, and the migratory and invasive capacity of the $\mathrm{CRC}$ cells was analyzed. The expression of FoxM1, E-cadherin and neuronal (N-) cadherin in the CRC cell lines was evaluated using qPCR and Western blot analysis. The relative expression levels of FoxM1 mRNA and protein were significantly increased in the CRC tissues compared with those in the colonic adenoma and wild-type mucosal tissue samples $(\mathrm{P}<0.01)$. In contrast, the relative expression levels of E-cadherin mRNA and protein were significantly decreased in the CRC tissues compared with in the colonic adenoma and normal mucosal tissues $(\mathrm{P}<0.01)$. FoxM1 overexpression and decreased E-cadherin expression were significantly associated with poor colonic tissue differentiation, lymph node metastasis and an advanced tumor-node-metastasis stage. Additionally, the increased expression of FoxM1 was associated with a decrease in E-cadherin expression $(\mathrm{P}<0.01)$. Furthermore, RNA interference-mediated FoxM1 knockdown significantly inhibited the proliferation, migration and invasion of CRC cells. Downregulation of FoxM1 expression significantly
\end{abstract}

Correspondence to: Professor Bao-Ying Fei, Department of Gastroenterology, Tongde Hospital of Zhejiang Province, 234 Gucui Road, Hangzhou, Zhejiang 310012, P.R. China

E-mail: feibaoying@hotmail.com

Key words: forkhead box M1, epithelial cadherin, neuronal cadherin, epithelial-mesenchymal transition, colorectal cancer increased E-cadherin expression and decreased N-cadherin expression. The results of the present study suggest that FoxM1 overexpression in tumor tissues is significantly associated with metastasis in CRC through the induction of EMT.

\section{Introduction}

Colorectal cancer (CRC) is one of the most common types of cancer worldwide. An estimated 142,820 novel cases and 50,830 mortalities due to CRC occurred in 2013 alone (1). In spite of significant improvements in current surgical techniques and chemoradiotherapy, the prognosis of patients with advanced CRC remains poor, and the morbidity remains high. Metastasis is responsible for $<90 \%$ of cancer-associated mortalities (2). Therefore, the identification of a novel, specific and efficient molecular target to prevent metastasis in CRC may be valuable in decreasing the mortality rate of patients with this disease.

Forkhead box M1 (FoxM1), a member of the forkhead family of transcription factors, is essential for cell cycle progression and is an important cell-cycle regulator that controls the transition from the $\mathrm{G}_{1}$ to the $\mathrm{S}$ phase (3-5). FoxM1 overexpression is observed in a variety of tumors and is associated with a poor prognosis in patients with cancer (6-9). Furthermore, the regulation of FoxM1 leads to the enhancement or inhibition of the invasion of pancreatic cancer (10), prostate cancer (11), ovarian cancer (12) and non-small cell lung carcinoma (NSCLC) (13) cells.

Epithelial-mesenchymal transition (EMT) is an essential phenotypic event that occurs during embryonic development, tissue remodeling and wound healing, and is a pivotal event that affects cancer cell invasion (14-17). EMT is hypothesized to be a critical mechanism of tumor metastasis (18-20). Ueno et al (21) demonstrated that the histological category of EMT in CRC was markedly prognostic, independent of staging factors, and exhibited an increased prognostic stratification power compared with the tumor and node stages.

The mechanisms underlying the FoxM1-induced metastasis in cancer remain unclear. Kong et al (13) identified that FoxM1 may be used as a prognostic indicator for patients with NSCLC and that FoxM1 promotes metastasis by inducing EMT in lung cancer cells. FoxM1 signaling serves an important role in tumor cell aggressiveness via the acquisition of the EMT phenotype in gastric cancer cells (22). The interaction between FoxM1 and EMT in CRC requires elucidation. 
In the present study, the prognostic role of FoxM1 overexpression in CRC was determined, and the association between FoxM1 expression and EMT in the metastasis of CRC was further investigated.

\section{Materials and methods}

Patients and tissue samples. A total of 91 paraffin-embedded colon cancer specimens were acquired from Zhejiang Provincial People's Hospital (Hangzhou, China). The samples were collected between January 2011 and December 2013. All cases were classified according to the World Health Organization Pathological Classification of Tumors, 2010 (23). Of the 91 individuals from which specimens had been collected, 55 were male and 36 were female. The patients' mean age was $54.4 \pm 10.8$ years (range, $41-76$ years). According to Dukes' classification, 16 patients were of grade A, whereas 25 were of grade B, 37 were of grade C and 13 were of grade D. None of the patients had received any radiotherapy or chemotherapy prior to the operation. The specimens were fixed in $10 \%$ formalin at room temperature for $24 \mathrm{~h}$, then embedded in paraffin. The freshly resected tumor and adjacent normal mucosal tissues from 30 cases were immediately stored at $-70^{\circ} \mathrm{C}$ until use. Paraffin-embedded blocks of colonic adenoma tissues were also included in the present study (61 cases). The present study was approved by the Ethics Committee of Zhejiang Provincial People's Hospital.

Immunohistochemistry. Immunohistochemical analyses on the tissues were performed using a Biotin-Streptavidin Horseradish Peroxidase Detection system (OriGene Technologies, Inc., Beijing, China), according to the manufacturer's protocol. Each $4 \mu \mathrm{m}$ section was deparaffinized in xylene, rehydrated in an alcohol gradient and rinsed with PBS. Antigen retrieval was carried out in $0.01 \mathrm{M}$ citrate buffer ( $\mathrm{pH} \mathrm{6.0)}$ ) for 3 min using the high-pressure retrieval method. The sections were then incubated with $3 \% \mathrm{H}_{2} \mathrm{O}_{2}$ for $10 \mathrm{~min}$, followed by $10 \%$ goat serum (Thermo Fisher Scientific, Inc., Waltham, MA, USA) for $15 \mathrm{~min}$, at room temperature, in order to block endogenous peroxidase and non-specific antigen binding.

Anti-FoxM1 rabbit monoclonal antibody (mAb) (cat. no. sc-501; dilution, 1:100; Santa Cruz Biotechnology, Inc., Dallas, TX, USA) and anti-E-cadherin mouse mAb (cat. no. UM800076; dilution, 1:100; OriGene Technologies, Inc., Rockville, MD, USA) were used as primary antibodies. The immunohistochemical evaluations were independently performed by two pathologists without knowledge of the clinical data. The immunoreactivity levels in each case were estimated using a light microscope (BX40; Olympus Corporation, Tokyo, Japan) by manually scoring the signal intensity $(0=$ negative, $1=$ weak, $2=$ moderate, $3=$ strong $)$ and the proportion of cells with positive staining $(0,<5 \% ; 1,5-25 \%$; $2,26-50 \% ; 3,51-75 \% ; 4,76-100 \%)$. The intensity and proportion scores were then multiplied to obtain a composite score: A score between 0 and 3 was defined as negative and a score between 4 and 12 was defined as positive.

Quantitative polymerase chain reaction ( $q P C R)$. Total RNA from tissues or cells was extracted using TRIzol reagent (cat. no. 15596026; Thermo Fisher Scientific, Inc.), according to the manufacturer's protocol. Complementary (c) DNA was produced with reverse transcription using the PrimeScript First Strand cDNA Synthesis kit (cat. no. DRR047A; Takara Biotechnology Co., Ltd., Dalian, China) according to the manufacturer's protocol. qPCR assays were performed using the MX3000P system (Stratagene; Agilent Technologies, Inc., Santa Clara, CA, USA) and the SYBR Premix ExTaq kit (cat. no. DRR042A; Takara Biotechnology Co.,Ltd.).GAPDH was used as an internal control. The primers for qPCR were as follows: FoxM1-Forward, GGAGCAGCGACAGGTTAAGG; FoxM1-Reverse, GTTGAT GGCGAATTGTATCATGG; GAPDH-Forward, TGAAGG TCGGAGTCAACGG; GAPDH-Reverse, CTGGAAGATGGT GATGGGATT. The reaction mixture consisted of $2 \mu \mathrm{l}$ of cDNA template in a final reaction volume of $20 \mu \mathrm{l}$; there were three replicates of each sample. Initial denaturation at $95^{\circ} \mathrm{C}$ for $5 \mathrm{~min}$ was followed by 40 cycles of amplification at $95^{\circ} \mathrm{C}$ for $10 \mathrm{sec}$, $58^{\circ} \mathrm{C}$ for $20 \mathrm{sec}$ and $72^{\circ} \mathrm{C}$ for $20 \mathrm{sec}$. A melting curve analysis was performed following the PCR cycles. Data was analyzed with SDS software v2.3 (Applied Biosystems; Thermo Fisher Scientific, Inc.). Relative expression levels were calculated using the $2^{-\Delta \Delta \mathrm{Ct}}$ method (24).

Cell culture. The colon cancer cell lines LoVo and SW480 were obtained from the Cell Bank of the Shanghai Chinese Academy of Sciences Institute (Shanghai, China). The cells were cultured in RPMI-1640 medium (cat. no. 11875-093) containing 10\% fetal bovine serum (FBS; cat. no. 10099-141; Gibco; Thermo Fisher Scientific, Inc.), 50 units $/ \mathrm{ml}$ penicillin and $50 \mu \mathrm{g} / \mathrm{ml}$ streptomycin, and were incubated at $37^{\circ} \mathrm{C}$ in a $5 \% \mathrm{CO}_{2}$ incubator.

Transient transfection with FoxM1 small interfering RNA (siRNA). In order to inhibit FoxM1 expression, FoxM1 siRNA (cat. no. sc-37615; Santa Cruz Biotechnology, Inc.) was used. LoVo and SW480 cells ( $2 \times 10^{5}$ cells/well) were seeded in 6-well plates, and cells were transfected with FoxM1 siRNA using siRNA Transfection Reagent (cat. no. sc-29528; Santa Cruz Biotechnology, Inc.), according to the manufacturer's protocol. Simultaneously, cells were transfected with scrambled siRNA (cat. no. sc-37007; Santa Cruz Biotechnology, Inc.) as a negative control. Following a $24 \mathrm{~h}$ transfection period, the cells were collected for later experiments.

Western blot analysis. For western blotting, cells were washed in PBS and lysed in a protein lysis buffer (including 1\% NP-40, 20 mmol/1 Tris-HCl (pH 8), $137 \mathrm{mmol} / 1$ $\mathrm{NaCl}, 10 \%$ glycerol and $2 \mathrm{mmol} / \mathrm{l}$ EDTA) by pipetting up and down to re-suspend. The lysates were gently rocked at $2-8^{\circ} \mathrm{C}$ for $30 \mathrm{~min}$ and centrifuged at $14,000 \mathrm{x}$ g for $5 \mathrm{~min}$, and the supernatant was transferred to a clean test tube. Sample protein concentrations were quantitated using the BCA method and then the extractions were aliquoted and stored at $-80^{\circ} \mathrm{C}$.

Total protein $(40 \mu \mathrm{g})$ was used for $10 \%$ SDS-PAGE. The proteins were electrotransferred onto polyvinylidene fluoride membranes using the semi-dry transfer method. The membranes were blocked with 5\% BSA for $2 \mathrm{~h}$ at room temperature and then incubated overnight with primary antibodies at $4^{\circ} \mathrm{C}$. The primary antibodies used were the previously described anti-FoxM1 rabbit and anti-E-cadherin monoclonal antibodies, as well as an anti-N-cadherin 
Table I. The rate of positive FoxM1 and E-cadherin expression in colonic tissues.

\begin{tabular}{|c|c|c|c|c|c|}
\hline \multirow[b]{2}{*}{ Tissue type } & \multirow[b]{2}{*}{ Total, $\mathrm{n}$} & \multicolumn{2}{|c|}{ FoxM1 expression, n (\%) } & \multicolumn{2}{|c|}{ E-cadherin expression, n (\%) } \\
\hline & & Negative & Positive & Negative & Positive \\
\hline Colorectal cancer & 91 & $21(23.1)$ & 70 (76.9) & 60 (65.9) & $31(34.1)$ \\
\hline Colorectal adenoma & 61 & $49(80.3)$ & $12(19.7)$ & $11(18.0)$ & $50(82.0)$ \\
\hline Normal colon & 32 & $31(96.9)$ & $1(3.1)$ & $4(12.5)$ & $28(87.5)$ \\
\hline
\end{tabular}

FoxM1, forkhead box M1.
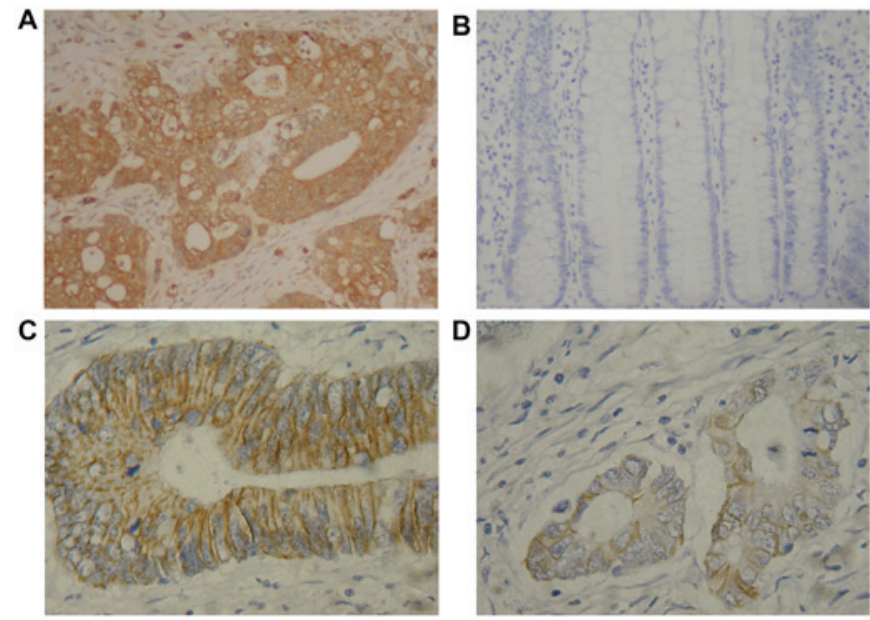

Figure 1. Representative immunohistochemical images demonstrating positive and negative expression of FoxM1 and E-cadherin in colorectal tissues (magnification, x200). (A) FoxM1-positive; (B) FoxM1-negative; (C) E-cadherin-positive; (D) E-cadherin-negative. FoxM1, forkhead box M1

(D4R1H) XP ${ }^{\circledR}$ rabbit monoclonal antibody (cat. no. 13116; dilution, 1:3,000; Cell Signaling Technology, Inc., Danvers, MA, USA). Following incubation with a HRP labeled secondary antibody (cat no. HA1001-100, 1:5,000, HuaAn Biotechnology Co., Ltd., Hangzhou, China) for $2 \mathrm{~h}$, the membranes were treated with an electrochemiluminescence reagent (cat. no. 36208ES60, Yishen Biotech Co., Ltd., Shanghai, China) and the chemiluminescence signal was detected using the Chemiluminescence Gel Imaging System (Bio-Rad Laboratories, Inc., Hercules, CA, USA). Three replicates were performed.

In vitro cell migration and invasion assays. In the migration assays, $1 \times 10^{5}$ colon cancer cells (LoVo or SW480) transfected with FoxM1 or negative control siRNA were plated (in triplicate) in the upper chambers of Transwell plates (EMD Millipore, Billerica, MA, USA) with a $8-\mu \mathrm{m}$ pore size membrane with $200 \mu \mathrm{l}$ FBS-free RPMI 1640 medium. A Matrigel-precoated membrane (cat. no. ECM554; EMD Millipore) was used to assess cell invasion. The degree of tumor cell migration and invasion was evaluated according to a previous protocol (25). After $24 \mathrm{~h}$ or $48 \mathrm{~h}$ of incubation, cells remaining on the top layers of the inserts were removed with a cotton swab. The cells on the lower surface of the membrane were fixed and stained with hematoxylin and eosin staining. The cell numbers in five random fields (with magnification, x200) were manually counted, and the mean value was calculated.

MTT assay. The effect of FoxM1 expression on the proliferation of colon cancer cells was evaluated using an MTT assay. LoVo or SW480 colon cancer cells that were transfected with FoxM1 or negative control siRNA were plated (in triplicate) in 96-well plates at $1 \times 10^{3}$ cells/well. The cells were incubated at $37^{\circ} \mathrm{C}$ in a $5 \% \mathrm{CO}_{2}$ incubator for between 1 and 7 days. Each day, $10 \mu \mathrm{l}$ MTT (5 mg/ml) (Sigma; Merck KGaA, Darmstadt, Germany) was added to each well and the cells were incubated for another $4 \mathrm{~h}$ prior to determination of cell viability. The medium was removed, and $150 \mu \mathrm{l}$ dimethylsulfoxide was added to dissolve the formazan product. The optical density at $570 \mathrm{~nm}$ (for measurement) and $630 \mathrm{~nm}$ (for background) was measured using a microplate reader.

Wound healing assay. siRNA-transfected LoVo or SW480 cells or negative control siRNA-transfected cells were seeded in Matrigel-coated $(50 \mu \mathrm{g} / \mathrm{ml}) 35-\mathrm{mm}$ diameter culture dishes. When the cultured cells reached $80 \%$ confluence, a sterilized pipette tip was used to mark a line of the same width on the bottom of each dish. Dishes were re-incubated at $37^{\circ} \mathrm{C}$, and images were captured 0 or $48 \mathrm{~h}$ after wounding. At $48 \mathrm{~h}$ after scratching, the medium was aspirated and the cells were rinsed with PBS and fixed in $100 \%$ ethanol for $10 \mathrm{~min}$ at room temperature. A wound-healing image of each group was then photographed with a phase-contrast IX71 microscope (Olympus Corporation).

Statistical analysis. All statistical analyses were performed using SPSS 13.0 statistical software (SPSS Inc., Chicago, IL, USA). The data was presented as mean \pm standard deviation $(n=3)$. Fisher's exact test and the $\chi^{2}$ test were used to evaluate the association between the clinicopathological variables and the expression of FoxM1 and E-cadherin. Spearman's rank correlation coefficients were used to quantify the association between the expression of FoxM1 and E-cadherin. $\mathrm{P}<0.05$ was considered to indicate a statistically significant difference.

\section{Results}

Expression of FoxM1 is increased and expression of E-cadherin is decreased in CRC tissues. Immunostaining of FoxM1 
Table II. Association between FoxM1 and E-cadherin expression and the clinicopathological factors of patients with colorectal cancer.

\begin{tabular}{|c|c|c|c|c|c|c|c|}
\hline \multirow[b]{2}{*}{ Variable } & \multirow[b]{2}{*}{$\mathrm{n}$} & \multicolumn{3}{|c|}{ FoxM1 expression } & \multicolumn{3}{|c|}{ E-cadherin expression } \\
\hline & & Negative & Positive & P-value & Negative & Positive & P-value \\
\hline Sex & & & & 0.19 & & & 0.15 \\
\hline Male & 55 & 12 & 43 & & 35 & 20 & \\
\hline Female & 36 & 9 & 27 & & 25 & 11 & \\
\hline Age, years & & & & 0.19 & & & 0.18 \\
\hline$<60$ & 41 & 10 & 31 & & 27 & 14 & \\
\hline$\geq 60$ & 50 & 11 & 39 & & 33 & 17 & \\
\hline Tumor localization & & & & 0.13 & & & 0.15 \\
\hline Rectum & 40 & 11 & 29 & & 25 & 15 & \\
\hline Colon & 51 & 10 & 41 & & 35 & 16 & \\
\hline Tumor differentiation & & & & 0.02 & & & $0.04^{\mathrm{a}}$ \\
\hline Poor & 25 & 4 & 21 & & 20 & 5 & \\
\hline Moderate & 44 & 7 & 37 & & 30 & 14 & \\
\hline Well & 22 & 10 & 12 & & 10 & 12 & \\
\hline Lymph node metastasis & & & & 0.01 & & & $<0.01$ \\
\hline Present & 48 & 6 & 42 & & 38 & 10 & \\
\hline Absent & 43 & 15 & 28 & & 22 & 21 & \\
\hline TNM stage & & & & 0.01 & & & 0.01 \\
\hline I+II & 41 & 15 & 26 & & 21 & 20 & \\
\hline III+IV & 50 & 6 & 44 & & 39 & 11 & \\
\hline
\end{tabular}

aComparison between all three groups. FoxM1, forkhead box M1; E-cadherin, epithelial cadherin; TNM, tumor-node-metastasis .

Table III. Spearman's correlation analysis between FoxM1 and E-cadherin expression in colorectal cancer patients.

\begin{tabular}{lccc}
\hline & \multicolumn{2}{c}{ E-cadherin expression } & \\
\cline { 2 - 3 } FoxM1 & Negative & Positive & P-value \\
\hline Negative & 3 & 18 & \\
Positive & 57 & 13 & $<0.01$ \\
\hline
\end{tabular}

FoxM1, forkhead box M1; E-cadherin, epithelial cadherin.

protein was primarily located in the cytoplasm of the tumor cells, and that of E-cadherin protein was primarily located in the cell membrane (Fig. 1). As included in Table I, the rates of positive FoxM1 and E-cadherin expression were 76.9\% (70/91) and $34.1 \%$ (31/91) in the CRC tissues, and $19.7 \%(12 / 61)$ and $82.0 \%(50 / 61)$ in the colorectal adenoma tissues, respectively. The expression of FoxM1 was increased significantly in the CRC tissues compared with the colorectal adenoma $(\mathrm{P}<0.01)$ and normal colonic $(\mathrm{P}<0.01)$ tissues. In contrast, E-cadherin expression was decreased significantly in the CRC tissues compared with the colorectal adenoma $(\mathrm{P}<0.01)$ and normal colonic $(\mathrm{P}<0.01)$ tissues. No significant differences in the FoxM1 or E-cadherin expression levels between the colorectal adenoma and normal colonic tissues were identified.
The association of FoxM1 and E-cadherin expression with the clinicopathological factors of the patients with cancer is presented in Table II. The expression levels of FoxM1 and E-cadherin were identified to be significantly associated with advanced tumor-node-metastasis (TNM) stage, poor tissue differentiation and lymph node metastasis.

As presented in Table III, an increase in FoxM1 expression was identified to be associated with a decrease in E-cadherin expression $(r=-0.60, \mathrm{P}<0.01)$.

FoxM1 and E-cadherin mRNA expression levels were determined using a qPCR assay in 30 fresh CRC tissue samples. The relative level of FoxM1 mRNA was significantly increased (Fig. 2) and the expression of E-cadherin mRNA was significantly decreased (Fig. 3) in the CRC tissues compared with the levels in the adjacent wild-type mucosal tissues $(\mathrm{P}<0.01)$.

FoxM1 knockdown decreases wound healing, in vitro migration and invasion, and proliferation of CRC cells. Downregulation of FoxM1 using siRNA inhibited cell migration using an in vitro wound healing assay. At $24 \mathrm{~h}$ after wounding, the healing ability of FoxM1 siRNA-transfected LoVo or SW480 cells was significantly suppressed (Fig. 4). Cell migration and invasion assays were performed using a Transwell system. Compared with the control cells, siRNA-transfected LoVo or SW480 cells exhibited a substantial decrease in migratory and invasive capacity (Fig. 5). An MTT assay demonstrated that the proliferative capability 

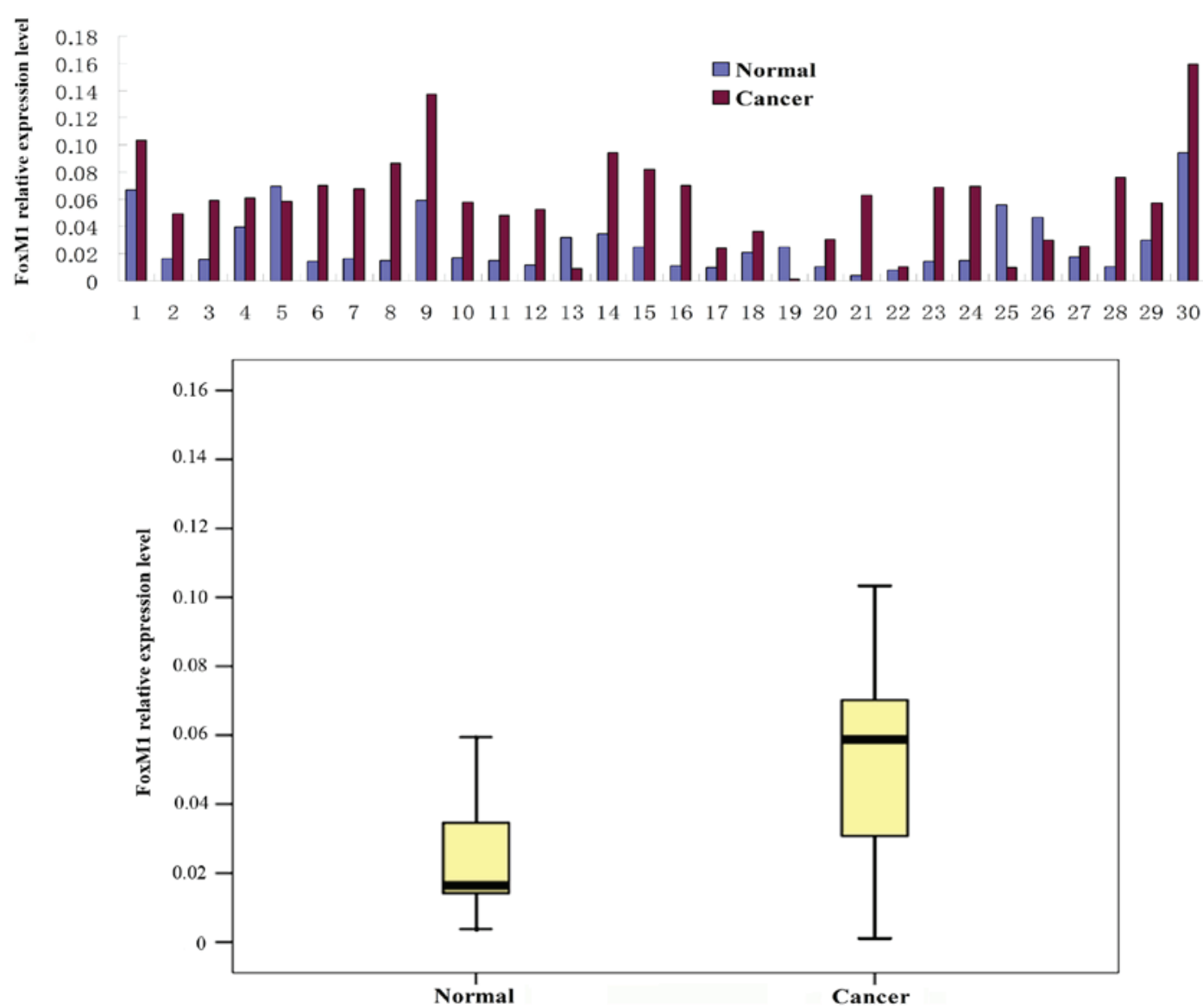

Figure 2. FoxM1 mRNA expression is increased in colorectal cancer compared with adjacent wild-type ('normal') mucosal tissue samples. Results are presented for individual samples, and as the median with the 25th and 75th percentiles. FoxM1, forkhead box M1.
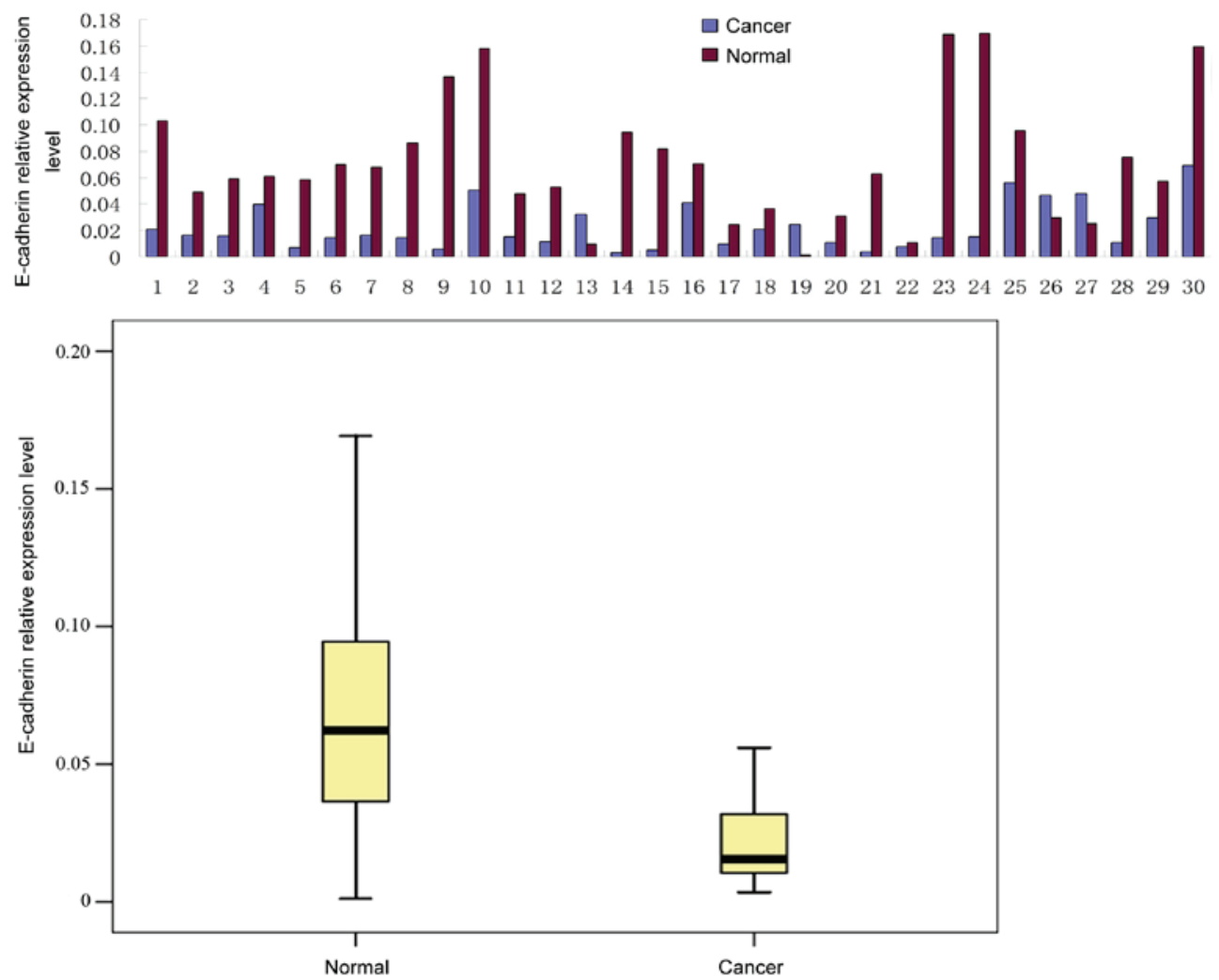

Figure 3. E-cadherin mRNA expression is increased in colorectal cancer compared with adjacent wild-type ('normal') mucosal tissue samples. Results are presented for individual samples, and as the median with the 25 th and 75 th percentiles. 


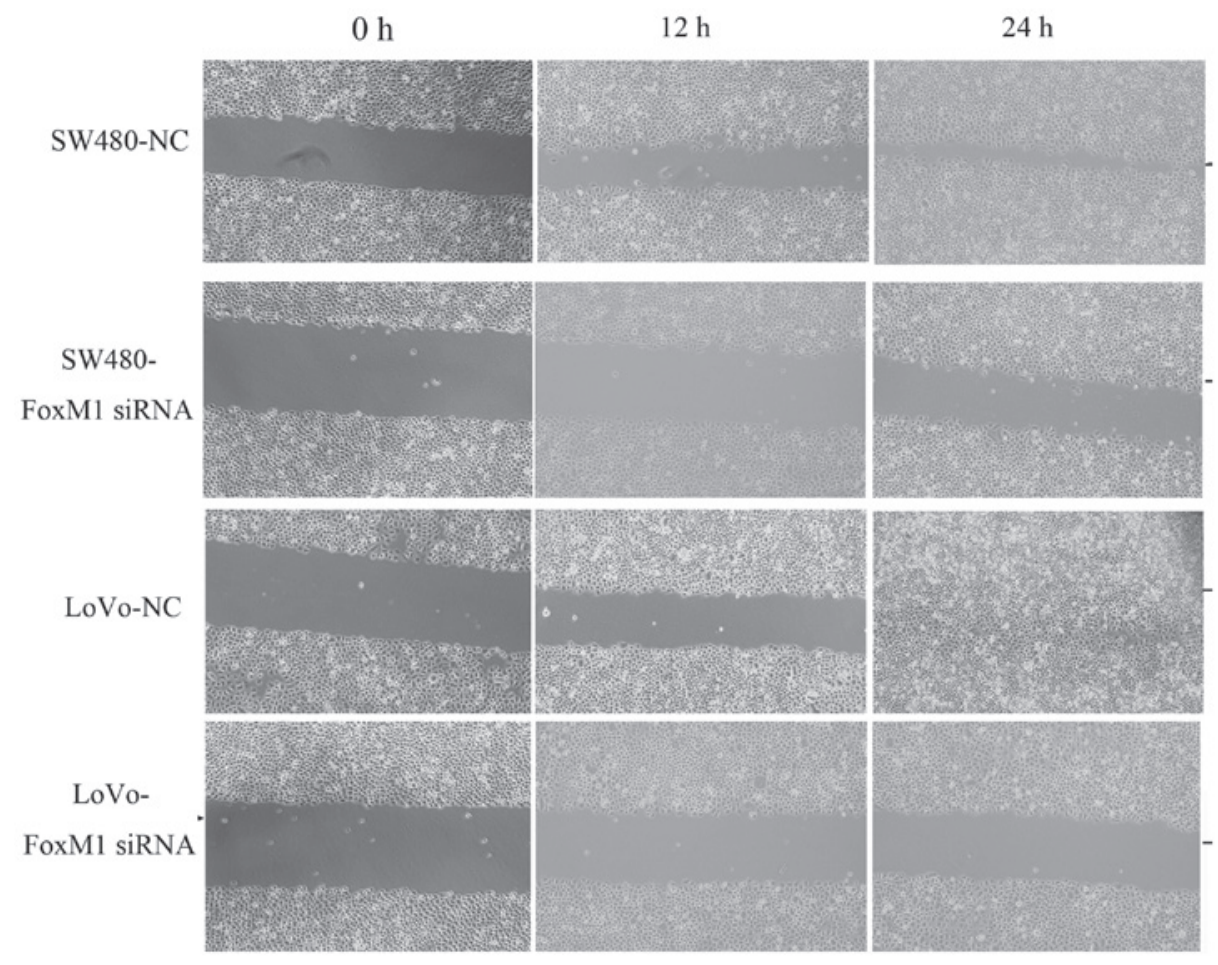

Figure 4. Inhibition of FoxM1 using siRNA decreases the migratory capacity of LoVo and SW480 cells as assessed using a wound healing assay. At $24 \mathrm{~h}$ after wounding, the healing ability of FoxM1 siRNA-transfected LoVo or SW480 cells was significantly suppressed compared with the NC siRNA-transfected cells. FoxM1, forkhead box M1; siRNA, small interfering RNA; NC, negative control.
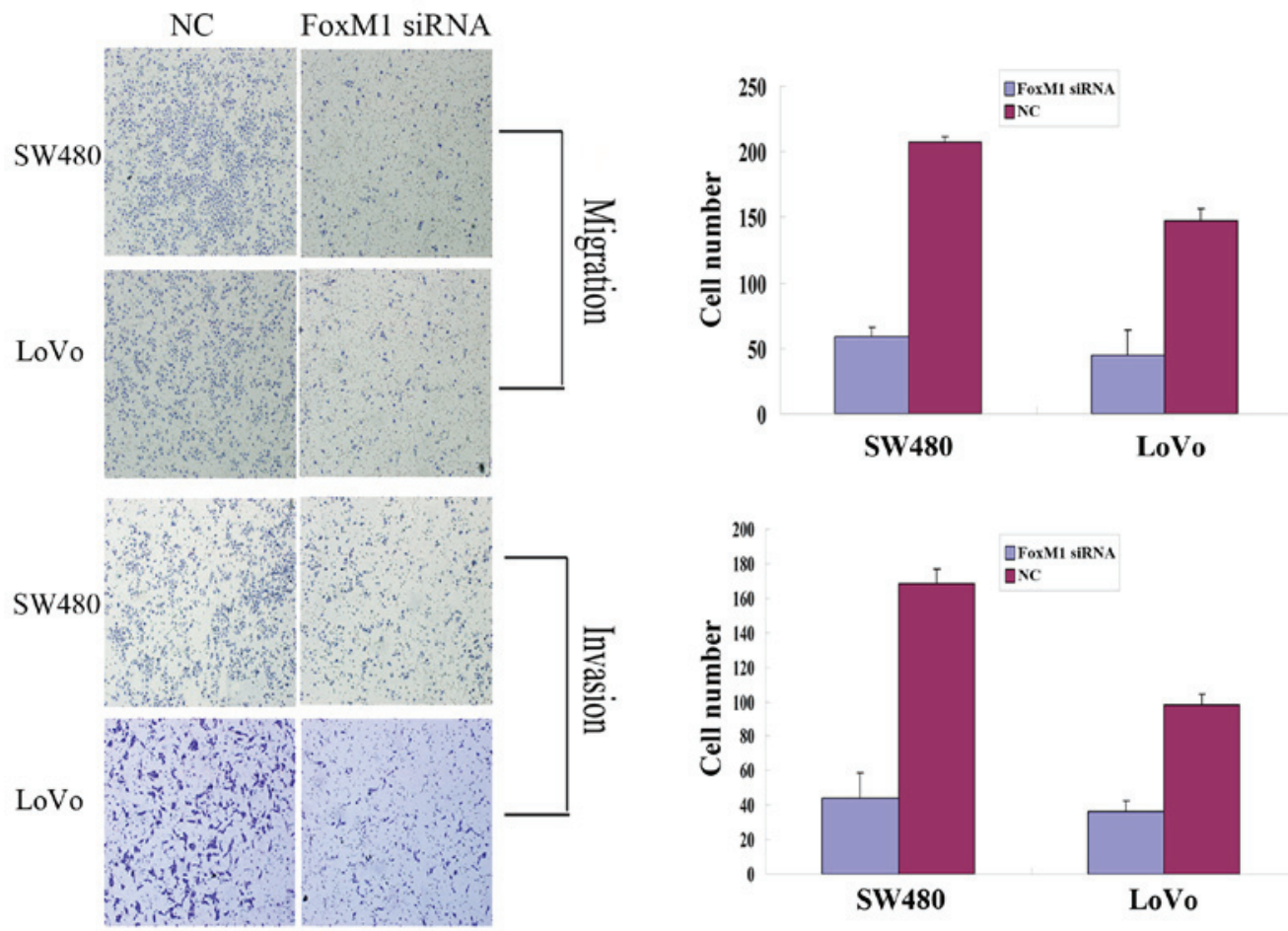

Figure 5. Inhibition of FoxM1 using siRNA decreases the migratory and invasive capacity of LoVo and SW480 cells as assessed using Transwell assays. Compared with the NC siRNA-transfected cells, the migratory and invasive capacity of the FoxM1 siRNA-transfected LoVo or SW480 cells was significantly decreased. FoxM1, forkhead box M1; siRNA, small interfering RNA; NC, negative control.

of the FoxM1 siRNA-transfected LoVo or SW480 cells was significantly decreased compared with the negative control siRNA-transfected cells (Fig. 6).
Downregulation of FoxM1 expression alters the expression of EMT-related proteins in CRC cells. To investigate the effect of FoxM1 knockdown on the EMT phenotype in CRC 

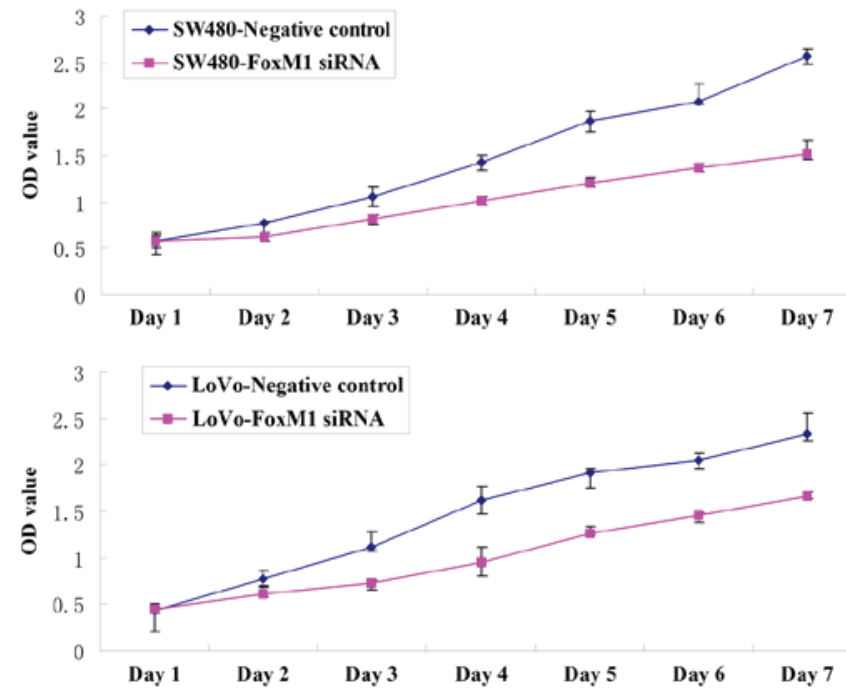

Figure 6. Inhibition of FoxM1 using siRNA decreases the proliferative capacity of colorectal cancer cells. Compared with the negative control siRNA-transfected cells, the proliferative capacity of the FoxM1 siRNA-transfected LoVo or SW480 cells was significantly decreased. FoxM1, forkhead box M1; siRNA, small interfering RNA; OD, optical density.

cells, FoxM1, E-cadherin and N-cadherin protein and mRNA expression levels were determined using Western blot and qPCR analyses. Following transfection of cells with FoxM1 siRNA, the expression levels of FoxM1 and N-cadherin protein and mRNA were significantly decreased, whereas the expression levels of E-cadherin protein and mRNA were increased in the LoVo or SW480 cells, compared with the negative control siRNA-transfected cells (Fig. 7).

\section{Discussion}

FoxM1 is overexpressed in a variety of tumors, including lung cancer, bladder cancer, clear cell renal cell carcinoma and early stage cervical cancer $(7,9,12,26)$. Furthermore, FoxM1 expression is significantly associated with a poor prognosis in many types of cancers, including gastric cancer, pancreatic cancer and lung carcinoma $(13,22,27)$. In addition, the results of the present study indicated that FoxM1 expression in tumor specimens is positively associated with advanced TNM stage, poor tissue differentiation and lymph node metastasis. siRNA-mediated FoxM1 inhibition decreased the proliferation and substantially decreased the migratory and invasive capacity of CRC cells. These results suggest that FoxM1 serves an important role in the invasion and metastasis of CRC. Recently, Yang et al (28) reported that FoxM1 overexpression was significantly associated with regional lymph node metastasis and tumor recurrence. Therefore, FoxM1 has the potential to be a novel therapeutic target in the treatment of CRC.

Metastasis involves a series of complex steps that include decreased adhesion, increased motility, cell attachment, matrix dissolution and migration (29). EMT is a key process in tumor metastasis and is associated with decreased E-cadherin levels, increased $\mathrm{N}$-cadherin levels and altered expression of several cytoskeletal proteins $(30,31)$. The decreased expression

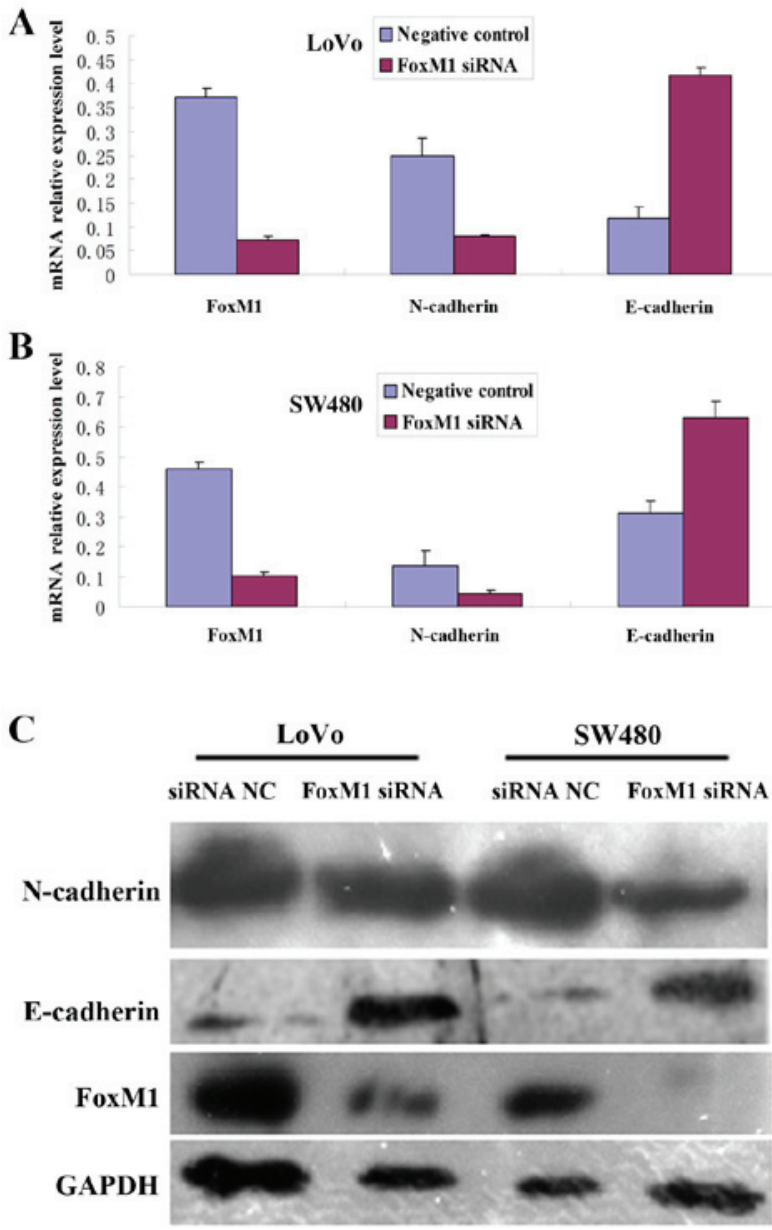

Figure 7. Inhibition of FoxM1 using siRNA decreases FoxM1 and $\mathrm{N}$-cadherin, and increases E-cadherin, protein and mRNA expression levels compared with NC siRNA transfection. mRNA expression levels were determined using the quantitative polymerase chain reaction, and protein levels were determined using western blot analysis. GADPH was used as a loading control. (A) mRNA expression in SW480 cells. (B) mRNA expression in LoVo cells. (C) Protein expression in LoVo and SW480 cells. FoxM1, forkhead box M1; siRNA, small interfering RNA; N-cadherin, neuronal cadherin; E-cadherin, epithelial cadherin; NC, negative control.

of E-cadherin promotes the invasion of tumor cells and is a defining characteristic of EMT (32).

A previous meta-analysis indicated that downregulated E-cadherin expression appeared to be associated with worse prognoses in Asian patients with CRC (33). In the analyses of the present study, the expression levels of E-cadherin protein and mRNA in the CRC tissues were significantly decreased compared with those in the adjacent wild-type mucosal tissues. Decreased E-cadherin expression was significantly associated with advanced TNM stage, poor tissue differentiation and lymph node metastasis in patients with CRC. These results are consistent with previous studies; for instance, Yun et al (34) recently reported that the loss of E-cadherin expression in stage III CRC is associated with a less favorable long-term prognosis in Korean patients. However, other EMT markers (including fibronectin and vimentin) were not identified to be associated with long-term survival outcomes. An improved understanding of the molecular pathways underlying EMT may reveal novel targets for the treatment of CRC by preventing this aspect of invasion. 
The present study has demonstrated that an increased level of FoxM1 expression was associated with a decreased level of E-cadherin expression and metastasis in patients with CRC, which preliminarily indicates that the association between FoxM1 and metastasis in CRC patients is associated with EMT. Previous studies have demonstrated that increased FoxM1 expression induces the occurrence of an EMT in pancreatic, lung and hepatocellular cancer cells $(13,35,36)$. In the present study, siRNA-mediated FoxM1 inhibition decreased $\mathrm{N}$-cadherin protein and mRNA expression and increased E-cadherin protein and mRNA expression levels in LoVo or SW480 siRNA-transfected CRC cells, which had markedly decreased migratory and invasive capacities. These results suggest that FoxM1 expression is associated with metastasis by regulating EMT in colorectal cells. The underlying molecular mechanisms and the question of whether FoxM1 directly or indirectly affects the expression of key EMT factors require further investigation.

The results of the present study suggest that FoxM1 expression is associated with metastasis in CRC. In the cell culture experiments, RNA interference-mediated FoxM1 knockdown significantly inhibited the proliferation, migration and invasion of CRC cells, and induced EMT of the CRC cells. The results of the present study raise the possibility of FoxM1 being an attractive target for CRC therapy.

\section{Acknowledgements}

The present study was supported by the Zhejiang Provincial Science Foundation of Medicine and Health (grant no. 2011KYA016).

\section{References}

1. Siegel R, Naishadham D and Jemal A: Cancer statistics, 2013. CA Cancer J Clin 63: 11-30, 2013.

2. Chaffer CL and Weinberg RA: A perspective on cancer cell metastasis. Science 331: 1559-1564, 2011.

3. Laoukili J, Kooistra MR, Brás A, Kauw J, Kerkhoven RM, Morrison A, Clevers H and Medema RH: FoxM1 is required for execution of the mitotic programme and chromosome stability. Nat Cell Biol 7: 126-136, 2005.

4. Sullivan C, Liu Y, Shen J, Curtis A, Newman C, Hock JM and Li X: Novel interactions between FOXM1 and CDC25A regulate the cell cycle. PLoS One 7: e51277, 2012.

5. Nakamura S, Hirano I, Okinaka K, Takemura T, Yokota D, Ono T, Shigeno K, Shibata K, Fujisawa S and Ohnishi K: The FOXM1 transcriptional factor promotes the proliferation of leukemia cells through modulation of cell cycle progression in acute myeloid leukemia. Carcinogenesis 31: 2012-2021, 2010

6. Liu LL, Zhang DH, Mao X, Zhang XH and Zhang B: Over-expression of FoxM1 is associated with adverse prognosis and FLT3-ITD in acute myeloid leukemia. Biochem Biophys Res Commun 446: 280-285, 2014.

7. Wu XR, Chen YH, Liu DM, Sha JJ, Xuan HQ, Bo JJ and Huang YR: Increased expression of forkhead box M1 protein is associated with poor prognosis in clear cell renal cell carcinoma. Med Oncol 30: 346, 2013.

8. Takata A, Takiguchi S, Okada K, Takahashi T, Kurokawa Y, Yamasaki M, Miyata H, Nakajima K, Mori M and Doki Y: Clinicopathological and prognostic significance of FOXM1 expression in esophageal squamous cell carcinoma. Anticancer Res 34: 2427-2432, 2014

9. Wang Y, Wen L, Zhao SH, Ai ZH, Guo JZ and Liu WC: FoxM1 expression is significantly associated with cisplatin-based chemotherapy resistance and poor prognosis in advanced non-small cell lung cancer patients. Lung Cancer 79: 173-179, 2013.
10. Huang C, Xie D, Cui J, Li Q, Gao Y and Xie K: FOXM1c promotes pancreatic cancer epithelial-to-mesenchymal transition and metastasis via upregulation of expression of the urokinase plasminogen activator system. Clin Cancer Res 20: 1477-1488, 2014.

11. Cai Y, Balli D, Ustiyan V, Fulford L, Hiller A, Misetic V, Zhang Y, Paluch AM, Waltz SE, Kasper S and Kalin TV: Foxm1 expression in prostate epithelial cells is essential for prostate carcinogenesis. J Biol Chem 288: 22527-22541, 2013.

12. Wen N, Wang Y, Wen L, Zhao SH, Ai ZH, Wang Y, Wu B, Lu HX, Yang H, Liu WC and Li Y: Overexpression of FOXM1 predicts poor prognosis and promotes cancer cell proliferation, migration and invasion in epithelial ovarian cancer. J Transl Med 12: 134, 2014

13. Kong FF, Qu ZQ, Yuan HH, Wang JY, Zhao M, Guo YH, Shi J, Gong XD, Zhu YL, Liu F, et al: Overexpression of FOXM1 is associated with EMT and is a predictor of poor prognosis in non-small cell lung cancer. Oncol Rep 31: 2660-2668, 2014.

14. Gonzalez DM and Medici D: Signaling mechanisms of the epithelial-mesenchymal transition. Sci Signal 7: re8, 2014.

15. Weber CE, Li NY, Wai PY and Kuo PC: Epithelial-mesenchymal transition, TGF- $\beta$, and osteopontin in wound healing and tissue remodeling after injury. J Burn Care Res 33: 311-318, 2012.

16. Yin SY, Peng AP, Huang LT, Wang YT, Lan CW and Yang NS: The phytochemical shikonin stimulates epithelial-mesenchymal transition (EMT) in skin wound healing. Evid Based Complement Alternat Med 2013: 262796, 2013.

17. Grant CM and Kyprianou N: Epithelial mesenchymal transition (EMT) in prostate growth and tumor progression. Transl Androl Urol 2: 202-211, 2013.

18. Ombrato L and Malanchi I: The EMT universe: Space between cancer cell dissemination and metastasis initiation. Crit Rev Oncog 19: 349-361, 2014.

19. Kwasnicki A, Jeevan D, Braun A, Murali R and Jhanwar-Uniyal M: Involvement of mTOR signaling pathways in regulating growth and dissemination of metastatic brain tumors via EMT. Anticancer Res 35: 689-696, 2015.

20. Yoshida T, Ozawa Y, Kimura T, Sato Y, Kuznetsov G, Xu S, Uesugi M, Agoulnik S, Taylor N, Funahashi Y and Matsui J: Eribulin mesilate suppresses experimental metastasis of breast cancer cells by reversing phenotype from epithelial-mesenchymal transition (EMT) to mesenchymal-epithelial transition (MET) states. Br J Cancer 110: 1497-1505, 2014.

21. Ueno H, Shinto E, Kajiwara Y, Fukazawa S, Shimazaki H, Yamamoto J and Hase K: Prognostic impact of histological categorisation of epithelial-mesenchymal transition in colorectal cancer. Br J Cancer 111: 2082-2090, 2014.

22. Miao L, Xiong X, Lin Y, Cheng Y, Lu J, Zhang J and Cheng N: Down-regulation of FoxM1 leads to the inhibition of the epithelial-mesenchymal transition in gastric cancer cells. Cancer Genet 207: 75-82, 2014.

23. Bosman FT, Carneiro F, Hruban RH, Theise ND (eds): WHO Classification of Tumours of the Digestive System. 4th editon. IARC Press, Lyon, 2010.

24. Livak KJ and Schmittgen TD: Analysis of relative gene expression data using real-time quantitative PCR and the 2(-Delta Delta C(T)) method. Methods 25: 402-408, 2001.

25. Hu J and Verkman AS: Increased migration and metastatic potential of tumor cells expressing aquaporin water channels. FASEB J 20: 1892-1894, 2006.

26. Liu D, Zhang Z and Kong CZ: High FOXM1 expression was associated with bladder carcinogenesis. Tumour Biol 34: 1131-1138, 2013.

27. Xia JT, Wang H, Liang LJ, Peng BG, Wu ZF, Chen LZ, Xue L, $\mathrm{Li} \mathrm{Z}$ and Li W: Overexpression of FOXM1 is associated with poor prognosis and clinicopathologic stage of pancreatic ductal adenocarcinoma. Pancreas 41: 629-635, 2012.

28. Yang K, Jiang L, Hu Y, Yu J, Chen H, Yao Y and Zhu X: Short hairpin RNA-mediated gene knockdown of FOXM1 inhibits the proliferation and metastasis of human colon cancer cells through reversal of epithelial-to-mesenchymal transformation. J Exp Clin Cancer Res 34: 40, 2015.

29. Quail DF and Joyce JA: Microenvironmental regulation of tumor progression and metastasis. Nat Med 19: 1423-1437, 2013.

30. Theys J, Jutten B, Habets R, Paesmans K, Groot AJ, Lambin P, Wouters BG, Lammering $\mathrm{G}$ and Vooijs M: E-Cadherin loss associated with EMT promotes radioresistance in human tumor cells. Radiother Oncol 99: 392-397, 2011. 
31. Chen L, Muñoz-Antonia T and Cress WD: Trim 28 contributes to EMT via regulation of E-cadherin and $\mathrm{N}$-cadherin in lung cancer cell lines. PLoS One 9: e101040, 2014.

32. Mohamet L, Hawkins K and Ward CM: Loss of function of e-cadherin in embryonic stem cells and the relevance to models of tumorigenesis. J Oncol 2011: 352616, 2011.

33. He X, Chen Z, Jia M and Zhao X: Downregulated E-cadherin expression indicates worse prognosis in Asian patients with colorectal cancer: Evidence from meta-analysis. PLoS One 8: e70858, 2013.

34. Yun JA, Kim SH, Hong HK, Yun SH, Kim HC, Chun HK, Cho YB and Lee WY: Loss of E-Cadherin expression is associated with a poor prognosis in stage III colorectal cancer. Oncology 86: $318-328,2014$
35. Huang C, Qiu Z, Wang L, Peng Z, Jia Z, Logsdon CD, Le X, Wei D, Huang $\mathrm{S}$ and Xie K: A novel FoxM1-caveolin signaling pathway promotes pancreatic cancer invasion and metastasis. Cancer Res 72: 655-665, 2012.

36. Meng FD, Wei JC, Qu K, Wang ZX, Wu QF, Tai MH, Liu HC, Zhang RY and Liu C: FoxM1 overexpression promotes epithelial-mesenchymal transition and metastasis of hepatocellular carcinoma. World J Gastroenterol 21: 196-213, 2015. 